\title{
Green Face of Packaging - Sustainability Issues of the Cosmetic Industry Packaging
}

\author{
Jelena Drobac ${ }^{1, *}$, Vesna Alivojvodic ${ }^{1}$, Predrag Maksic ${ }^{1}$ and Marina Stamenovic ${ }^{1}$ \\ ${ }^{1}$ Belgrade Polytechnic, Brankova 17, Belgrade, Serbia
}

\begin{abstract}
Packaging is a steadily growing industry that faces many challenges as well. Ever growing consumer expectations, though competition, technological advances don't come even close to the huge issue of sustainability within the industry. Packaging for the beauty industry is dependable on the looks more than any other with massive changes in the recent years since extensive grooming became a part both genders lifestyle today and spreading those standards across the globe. The global cosmetic packaging market was valued at USD 25.9 billion in 2018 and is expected grow $4.8 \%$ in the next 5 years flying high on the innovative package designs, increasing demand for cosmetics focused on the middle class and youth as well as e-commerce. The first stepping stone is that more than half of the materials used for the massive cosmetic industry packaging are plastics. Finding alternatives and making a shift to a greener and circular way will be a challenge in the years to come.
\end{abstract}

\section{Introduction}

Consumer product companies have evolved from small firms to large global companies. We know these products today as global brands that are mostly sold by a small number of global corporations. Today packaging of beauty products is a steadily growing industry that faces many challenges. Ever growing consumer expectations, though competition, technological advances don't come even close to the huge issue of sustainability within the industry.

Packaging for the beauty industry is dependable on the looks more than any other with massive changes in the recent years since extensive grooming became a part both genders lifestyle today and spreading those standards across the globe. The first stepping stone is that more than half of the materials used for the massive cosmetic industry packaging are plastics. Finding alternatives and making a shift to a greener and circular way will be a challenge in the years to come. In the following paper we will analyze these alternatives and show where greener and circular ways are taking cosmetic industry packaging today.

\section{Beauty in context}

\footnotetext{
*Corresponding author: jdrobac@politehnika.edu.rs
} 


\subsection{Beauty as a term}

Beauty in a particular context can mean "indisputable excellence", something like health. A visited place of beauty that is more or less indisputable is visited by the beauty of man - the outer and inner beauty. Beauty of body and face, beauty of soul. By relocating the term beauty to the world of creation, one cannot escape the fact that beauty in the context of creation comes to the "exaltation of the beauty of art" [1]. Although in Art (external) beauty is an initial and certainly superficial characteristic, it actually comes from the inner beauty of the art work itself. When we talk about art, we consider not just fine arts, but we consider design as well.

In the world of art, and even in design, beauty is an immutable, permanent, selfcontained category. It is fixed in forms that emerge from art, it is deep, it is not superficial, it can be hidden, it is sometimes disturbing, indestructible, it is not ephemeral as time and is a fact in nature. Beauty is a lofty term for art and design, even the ideal one strives for. In life, beauty does not have to be obligatory, while in art and design it is an indispensable element.

Beauty cannot be separated from the social and cultural context in which it is defined. Beauty reaches agreement with the social context, which is inconsistent with class, race and other social elements. Looking at the historical context of beauty, it can be portrayed as the possession of the elite or elitist. For example, the field of photography is the segment of art where beauty is most triumphant. The photographic eye or the photographic way of observing the world around us has actually led to the beauty of being appreciated much more than before.

In fact, when one looks at the whole history of beauty, when one looks at the present and assumes the future, beauty can be illustrated as an ideal and as perfection. It identifies with the body of man, with the body of the animal, with spirit or soul, with existence itself, with nature and health.

Beauty is there to admire and observe, which brings us to the beauty industry. It brings us to all those beauty magazines, salons, products, and so on. Beauty is an integral part of the industry of the beautiful, a history of idealization and of solace. As Susan Sontag says: "The beauty that is human, and the beauty that is made (art) - both raise the fantasy of possession." [1]

\subsection{The globalization of the beauty industry}

In the following text, we will present the development of the history of the beauty industry in the context of globalization, in order to understand the current state of this industry. Like many other consumer products, beauty products had its own development. The companies that created these products have evolved from small firms to large global companies. We know these products today as global brands that are mostly sold by a small number of global corporations.

It is worth mentioning that this industry produces products that are used on the body of humans for beauty purposes. Here we are talking about cosmetic products such as soaps, deodorants, baths, and all other products for children and adults. The greatest development of this industry occurred in the second half of the twentieth century. [2]. The modern beauty industry is actually based on hygiene concerns. Leaning on this, hygiene is identified with social morality and a way of placing it on the social hierarchy.

It all began in the nineteenth century with the technological revolution of soap making. Then came products like toothpaste, and others. Of course, products and sales were accompanied by marketing, especially in the United States. For example, Colgate began its sale in 1873 by selling toothpaste packaged in jars. It was not until 1896 that the toothpaste 
tube as we know it today was created. A similar happened with shaving products. Gillette, a metal maker, offered a safety razor to the market in 1901, and only later sold shaving creams. The products were made by pharmacists and chemists [2]. One pharmacy designed the Nivea Cream - the first long-lasting moisturizer.

Between World War I and World War II, the beauty industry increased significantly. In 1915, retailing cosmetics in the United States was \$ 45 million, and in 1920 it even reached $\$ 129$ million [3]. Then a number of companies developed that produced cosmetics, makeup, skin and hair care products, toilet soaps and so on. These include companies such as Max Factor, Maybelline or Helene Curtis.

Contemporary beauty industry overlapped with the accelerating globalization during the twentieth century. The value of companies and the quick development of this industry have led the entire industry to take on a quasi-ideological role. Certainly, toilet soaps have led the entire process of globalization. For example, in the United States and European countries soap was widely sold.

The end of World War II showed that the United States represented the largest beauty market. The communist world, on the other hand, was lagging behind this market due to the poor purchasing power of the population. In the 1950s, North America accounted for twothirds of the consumption of makeup and personal care products [3]. With the development of technology in the 1960s and 1970s, the potential for growth and globalization of this industry emerged.

In developing countries, products coming from the Americas and Europe, such as soaps, toothpaste, etc., have been replaced with traditional, mostly craft-made cosmetic products. In the globalization process of the 1970s, companies began to build factories and manufacturing facilities in third world countries. Other companies included Gillette, Palmolive and Unilever [2].

We should be aware of that cosmetic brands have transmitted their beauty ideals to these countries. For example, American companies relied on their views of beauty that were largely based on popular culture in the form of Hollywood movies or fashion. At the end of the century, when globalization was on the rise, marketing pushed beauty products to developing countries. To this day there is a great struggle of companies in the global market. Surely, besides the product, the product packaging has played a huge role and therefore the design of the packaging.

The globalization of the beauty industry, according to the literature, has not produced homogeneity in the concept of beauty [2]. After the fall of the Berlin Wall, heavy globalization was followed by increasing segmentation by gender, ethnicity, age and more. Yet, the ideals of beauty have become widespread around the world. In the historical context of corporate strategy, they have to some extent united the understanding of beauty around the world, and certainly packaging design has played a key role there.

\section{Beauty packaging industry today}

Packaging for the beauty industry is dependable on the looks more than any other with massive changes in the recent years since extensive grooming became a part both genders lifestyle today and spreading those standards across the globe. Design plays a huge role in the game a big players have a new market they are trying to please - dominantly Muslim Asia with expectations of doubling market.

Back in 2014, the sales were $\$ 20$ billion and expectance is to reach $\$ 45$ billion by the end of 2020. Muslim culture requires a lot of adaptations from process to the visuals. Expecting this culture of "halal" quality means that only certain types of oil can be used, and all used materials are always indicated on the packaging. Also, the visuals like material, 
shape and imagery must not be "haram" and prohibited under Shariat law. Thus, labels on packaging showing female body features are strictly prohibited.

Today, packaging is a steadily growing industry with the global cosmetic packaging market valued at USD 25.9 billion in 2018 and is expected grow $4.8 \%$ in the next 5 years [4]. It is fast growth owes a lot to the innovative package designs, increasing demand for cosmetics focused on the middle class and youth as well as e-commerce.

\subsection{Green beauty - inside and out}

Reading about market peaks and numbers sounds delightful but it is not all rosy in the cosmetic packaging industry. Just like the all the other segments of the packaging industry, cosmetics packaging will have to face the challenges of the modern living: packaging for the one-member household, online shopping demands, personalized packaging expectations and smart packaging. Ever-growing consumer expectations, though competition, technological advances don't come even close to the huge issue of sustainability as the biggest obstacle in the industry. It is estimated that 166 billion of packaging units is sold [4] globally, with $61 \%$ market share in 2015 being plastic packaging like as bottles, jars, tubes etc. Plastics rules supremely as a dominant material for cosmetics and personal care products and it is not showing signs of slowing down. As the industry grows each year, as bottles remain the primary packaging form with a $28 \%$ share of the global market [4].

Finding alternatives and making a shift to a greener and circular way will be a challenge in the years to come. Many consumers, especially in Europe, the cosmetic epicenter of consumption with 77 billion euros annually [4], are opting for green cosmetic products inside and out. At the top of the wish list is nature-friendly packaging. This means that picky European shoppers are choosing more and more vegan products, and the packaging must be made of natural materials with as little resources as possible - in terms of production, transportation and waste.

Over the years, German cosmetic giant DM created its natural cosmetics brand Alverde. Recently they presented foldable boxes that were printed with biodegradable offset ink and made $80 \%$ of recycled raw materials. These inks are made using green electricity, originating from renewable sources that require $76 \%$ less carbon dioxide and contain no minerals.

In Germany, one of the seven world's leading spray can consumers, DM paired with Unilever in a recycling programme called R'cycle!. They collected spray cans and made almost 800 bicycles from the recycled aluminum for children charities.

The Frosch brand, another German giant, has unveiled $100 \%$ high density polyethylene packaging plastic recycling waste. These "Frosch Senses" shower bottles made from PE-HD post-consumer recyclables (PCR) have been on the market since mid2019.

Many other big global players are running for innovation in recycling like P\&G's with its PureCycle, see by some as a possible breakthrough on the global recycling market. Others turn to refill tactics like Estée Lauder's make-up line MAC Cosmetics. It's 'Back-to- M.A.C Programme' encourages consumers to return empty primary packaging to store. In exchange for six returned cosmetics empties shoppers get a free eye shadow, while sub-contractors take care of recycling. The same tactics is used in Austria every returned packaging unit from the Vichy is marked with a stamp in a recycling passport and for six stamps you get a free Vichy shower gel.

Sustainability frontrunner, UK based Lush Cosmetics recently announced that it will replace reusable aluminum containers with cork containers. Cork is durable, waterproof and $100 \%$ biodegradable. They partnered up with authorities in Portugal, number one producer 
of the cork in the world, to create a sustainable harvesting program while ensuring locals'benefit.

France and Germany make 53\% of the huge European cosmetic market [4]. Therefore, the French cosmetic business ZAO Make Up has made a complete range of packaging products made out of bamboo. Bamboo, which is highly renewable and extremely durable, has allowed them to create a sleek and modern design that exudes luxury and nature. All ZAO products are made from natural, vegan materials while the packaging can be refilled, so bamboo packaging can only be purchased once.

With the expansion of e-commerce, the practicality of packaging is becoming more important while the volume, weight and handling during transport are becoming crucial. In this regard, online retailers are increasingly turning to materials that are lightweight and durable while design is becoming increasingly minimalist. Plastics could be in certain cases replaced with glass, if it becomes less heavy and breakable. This opens the door for experiments, nano-materials or completely new technology.

\subsection{New materials for beauty industry}

Beside bamboo - seaweed, cornstarch, mushroom fibers, avocado nuts are now gained popularity as plastic alternatives. Bioplastics are highly durable and made from corn that can be used to make bottles, films and other containers. New eco cellophane "NatureFlex" in made out of wood pulp, while biodegradable plastic similar to polystyrene is made out of milk.

Seaweed is used to make the first eatable water container. The material called "notpla" by the British start-up Ooho could be sustainable solution to the problem of the ecological footprint of plastic bottles. Similarly to this, USA company Pacific Shaving Co. designed "Single Use Minis Shaving Cream". One dose of shaving cream is packaged in water-soluble film that vanishes when put under water stream. These resolvable pouches are made from high-barrier PET film laminated to LLDPE (linear-low-density polyethylene). This packaging hits many high tones of the contemporary packaging goals:

- it is single use package

- $\quad$ it is light to carry around

- $\quad$ it is zero waste

- $\quad$ it complies to the flight regulation laws

An alarming thought - if we are to assume that all of us use ten plastic bottles of shower gels and shampoo each year, this amounts to 75,000 tons of plastic waste - enough to fill about a thousand Olympic swimming pools [6]. Around $90 \%$ of shampoo and gels is water and about $80 \%$ of it's plastic packaging ends up in landfilled and water. No wonder that a lot of the efforts are pushed in this direction. One of the initiatives came from New Zealand, from Brianne West, who created Ethique, cosmetic company that produces shampoos and conditioners as solid bars. Her products are natural and come in a plastic free form.

Another design arouses the attention of the social media, academics and companies. Product designer Jonna Breitenhuber created SOAPBOTTLE-biodegradable, zero waste packaging made from soap. Concept of her master project at UDK Berlin is "packagingfree cosmetics by turning the product into its own packaging". Each bottle consists of 80 grams of soap and can hold one liter of liquid, lasting for approximately a month, thanks to its water-insoluble layer coating that slows down the dissolving process [6]. The empty bottle can be transformed into a hand soap or into detergent by grating it down and adding soda and natron. Her design is minimalistic, with strong forms.

In the similar tone, Mi Zhou, Material Futures master's degree student from Central Saint Martins in London [7]. She has created bottles and jars made of soap called Soapack 
by using vegetable oil-based soap that melts away once they are empty. A thin layer of beeswax is used to line the bottles to make them waterproof, preventing the liquid contents from leaking and even the "paper" instructions dissolve in water $[7,8]$. Differently from Breitenhuber's project, Zhou created a much more sophisticated aesthetics and shapes while pastel gradients are achieved using pigments from minerals, plants, and flowers.

\section{Conclusion}

The packaging industry has seen a record increase in production volume in recent years, while at the same time facing growing public pressure to reduce the amount of packaging materials used to package products, primarily. The increasing need to change the usual concept of product packaging is linked to the requirements of sustainable development and the environmental impact of packaging materials (especially in the post consumption phase) plastics, but also caused by changes in people's lifestyles as well as contemporary market demands that introduces the concept of personalized packaging, smart packaging and online shopping. The need to find new materials that are acceptable from an environmental point of view, while striving to preserve the market, influences the development of a whole new area of packaging materials for which it is necessary to connect different branches of science, different sectors of production and turn to a new approach in packaging design plastics [9]., which will be able to meet all set requirements.

\section{References}

1. S. Sontag, Vol. 134, No. 4, MIT Press, 208-213 (2005)

2. G. Jones, Blonde and Blue-Eyed? Globalizing Beauty, c.1945-c.1980, The Economic History Review, New Series, Vol. 61, No. 1, Wiley, 125-154 (2008)

3. J. Willett (ed.), The American Beauty Industry Encyclopaedia, Greenwood Press, Santa Barbara, California (2010)

4. Growth of the global cosmetics packaging industry (2017) https://www.interpack.com/en/TIGHTLY_PACKED/SECTORS/COSMETICS_PACKAGI NG/News/Growth of the global cosmetics packaging industry (visited 2020, April 18)

5. P. Demetrakakes (2017, March 17). Zero-waste shaving cream pods are convenient and travel friendly. Retrieved from https://www.packagingdigest.com/flexiblepackaging/zero-waste-shaving-cream-pods-are-convenient-and-travel-friendly-2017-03-17 (visited 2020, April 18)

6. K. Barba-Court (2019, October 14). This ingenious liquid soap packaging by Jonna Breitenhuber is made from soap. Retrieved from https://plainmagazine.com/jonnabreitenhuber-soapbottle/ (visited 2020, April 20)

7. E. Taggart (2019, July 12). These Elegant Bottles Are Made of Soap Instead of Plastic to Create Zero Waste. Retrieved from https://mymodernmet.com/plastic-packagingalternative-soapack-mi-zhou/ (visited 2020, April 20)

8. M. Waqas, I. Yuncheol, K. WooJeonc, J. of Clean. Prod., Vol. 245, Elsevier Ltd, 118827, (2020)

9. B. Mau, J. Leonard, Institute without Boundaries, Massive change, Phaidon Press, UK (2004) 